\title{
ÉPOCAS DE MANEJo QUímico DE Brachiaria decumbens ANTECEDENDo o Plantio Direto de Soja ${ }^{1}$
}

\author{
Brachiaria decumbens Management Times in Soybean under no Tillage System
}

\author{
NUNES, A.S. ${ }^{2}$,TIMOSSI, P.C. ${ }^{3}$, PAVANI, M.C.M.D. ${ }^{4}$ e ALVES, P.L.C.A. ${ }^{4}$
}

\begin{abstract}
RESUMO - O manejo químico da cobertura vegetal e a manutenção da palhada sobre o solo são preocupações comuns para os produtores que adotam o sistema plantio direto na região dos cerrados. Com o objetivo de estudar a influência da época de manejo químico de $B$. decumbens sobre o desenvolvimento e a produtividade da cultura da soja em sistema plantio direto, foram realizados dois ensaios a campo, respectivamente, com os cultivares BRS 154 e MG/BR 46-Conquista, no ano de 2003. Em cada ensaio, testaram-se quatro épocas de manejo de $B$. decumbens antecedendo a semeadura da soja (28, 14,7 e 0 dias), utilizando-se o herbicida glifosato. Os ensaios foram conduzidos em delineamento inteiramente casualizado, utilizando-se três repetições no primeiro e quatro no segundo. Determinou-se a matéria seca da cobertura vegetal e avaliou-se a reinfestação de $B$. decumbens. Na cultura da soja, foram determinados: altura de inserção da primeira vagem, número de vagens por planta, umidade dos grãos, massa de 100 grãos e produtividade. Com base nos resultados obtidos, conclui-se que a época mais adequada para o manejo químico de $B$. decumbens com glifosato situa-se entre 7 e 14 dias antes da semeadura da cultura da soja e que a escolha da época de manejo químico da cobertura vegetal afeta de forma decisiva o desenvolvimento e a produtividade da cultura.
\end{abstract}

Palavras-chave: cobertura vegetal, glifosato, Glycine max, produtividade.

ABSTRACT - Cover crop management and straw maintenance over the soil are common concerns for producers adopting the no tillage system in the cerrado region in Brazil. In order to study the influence of $\boldsymbol{B}$. decumbens time management on soybean development and productivity under no tillage system, two assays were carried out using the cultivars BRS 154 and MG/BR 46-Conquista. For each cultivar, four $\boldsymbol{B}$. decumbens management times prior to sowing of soybean $(28,14,7$ and $O$ days) were tested using glyphosate for weed control, in three replicates for cultivar BRS 154 and four replications for $M G / B R$ 46-Conquista, in a completely randomized design. B. decumbens dry weight and reinfestation were evaluated. Height of first pod insertion, number of pods per plant, grain moisture, weight of 100 seeds and productivity were evaluated in soybean crop. Based on the results obtained, it could be concluded that the most appropriate time for the management of $\boldsymbol{B}$. decumbens with glyphosate is between 7 and 14 days before soybean sowing and that choice of time management of the cover crop has a decisive effect on the development and productivity of the crop.

Keywords: cover crop, glyphosate, Glycine max, productivity.

Recebido para publicação em 15.4.2008 e na forma revisada em 5.6.2009.

2 Engo-Agr ${ }^{\circ}$, M.Sc., aluno de Doutorado do Programa de Pós-Graduação em Agronomia da Universidade Federal da Grande Dourados - UFGD, Rua Hayel Bon Faker, Jd. Cramuru, 79806-000 Dourados-MS, <anisionunes@yahoo.com.br>; ${ }^{3}$ Professor, Doutor da Universidade Estadual de Goiás - UEG, Itajaí-GO; ${ }^{4}$ Professores Doutores da Faculdade de Ciências Agrárias e Veterinárias - FCAV/Unesp, Jaboticabal-SP. 


\section{INTRODUÇÃO}

A dificuldade na formação e manutenção da palhada sobre o solo na região dos cerrados está diretamente associada ao clima, caracterizado por um regime de chuvas com precipitações concentradas nos meses de outubro a março e pelas altas temperaturas, que influenciam a atividade microbiana do solo (Timossi et al., 2006). Desse modo, a escolha da espécie formadora da palhada e o seu manejo químico assumem grande importância para o sucesso do sistema.

As espécies do gênero Brachiaria, de maneira geral, vêm sendo consideradas opções proeminentes na formação da palhada para o sistema plantio direto, devido à boa produção de matéria seca e à alta relação $\mathrm{C} / \mathrm{N}$ de sua composição (Nunes et al., 2006). Entretanto, a utilização dessa palhada ainda necessita de informações que esclareçam sobre o momento correto de manejo químico, para que este não influencie negativamente a cultura sucessora.

Souza et al. (2006), avaliando os efeitos alelopáticos de $B$. decumbens sobre o crescimento inicial de milho, arroz, trigo, soja, feijão, algodão e a dinâmica do nitrogênio no solo, concluíram que a incorporação da matéria seca da parte aérea de $B$. decumbens reduziu significativamente os teores de nitrato no solo em todos os estudos realizados. Entretanto, segundo Maciel et al. (2003), esses efeitos não são observados quando se adota o sistema plantio direto.

Entre as estratégias comumente utilizadas no manejo químico da cobertura vegetal para a semeadura da soja em sistema plantio direto, destaca-se o manejo químico, que pode ser realizado imediatamente antes da semeadura, entre sete e dez dias antes da semeadura ou entre dez e vinte dias antes da semeadura (Oliveira Jr. et al., 2006). O manejo químico realizado com glifosato em períodos menores que 14 dias antes da semeadura da soja pode influenciar negativamente as micorrizas que colonizam as raízes de soja (Silva et al., 2006).

Em áreas com grande cobertura vegetal (de 40 a $50 \%$ de cobertura do solo) as culturas semeadas logo após o controle químico das coberturas apresentaram clorose das folhas no período inicial, com redução no desenvolvimento vegetativo, podendo implicar queda de produtividade (Procópio et al., 2006). Melhorança \& Vieira (1999) observaram que a semeadura de soja em áreas de pastagem, realizada em período inferior a 15 dias após a aplicação do herbicida, resultou em clorose acentuada na parte aérea, especialmente na fase inicial da cultura. Peixoto \& Souza (2002) verificaram que a produtividade da soja foi diminuída em até $13,9 \%$ quando esta foi semeada imediatamente após o manejo químico do sorgo.

Segundo Santos et al. (2007), o intervalo entre o manejo químico da cobertura vegetal e a semeadura da soja deve ser de pelo menos sete dias, pois o manejo químico e a semeadura no mesmo dia, além de afetarem o desenvolvimento da cultura, promovem efeito negativo na atividade de microrganismos do solo. Constantin et al. (2000), avaliando a interação entre diferentes sistemas de manejo químico antecipado e formas de controle de plantas daninhas após a emergência da soja, concluíram que a antecipação do manejo químico possibilita melhor controle das plantas daninhas e a redução no uso de herbicidas de controle complementar.

O objetivo deste trabalho foi estudar a influência da época de manejo químico de $B$. decumbens antecedendo a semeadura da soja sobre o desenvolvimento e a produtividade de dois cultivares no sistema plantio direto.

\section{MATERIAL E MÉTODOS}

Foram realizados, simultaneamente, dois ensaios de campo com a cultura da soja, em 2003, na área experimental pertencente à Fazenda Santa Cecília, no município de Batatais (20 $52^{\prime} 36^{\prime \prime}$ de latitude sul, $47^{\circ} 35^{\prime} 6^{\prime \prime}$ de longitude oeste e altitude de $862 \mathrm{~m}$ ), no Estado de São Paulo. Em um dos ensaios, foi utilizado o cultivar de soja BRS 154 e, no outro, o cultivar MG/BR 46-Conquista. O cultivar de soja MG/BR 46-Conquista é recomendado para os Estados de MG, SP, MT, GO e DF, possui hábito de crescimento determinado, ciclo médio, $0,82 \mathrm{~m}$ de altura média de plantas e 0,15 m de altura média de inserção da primeira vagem. Resistente ao acamamento, a população de plantas recomendada situa-se entre 240.000 
e 350.000 plantas ha-1. O cultivar de soja BRS 154, desenvolvido pela Fundação PróSementes/Embrapa, é caracterizado pelo ciclo precoce, hábito de crescimento determinado e pela baixa exigência em fertilidade do solo (COMIGO, 2005). A população de plantas recomendada situa-se entre 300.000 e 360.000 plantas ha ${ }^{-1}$. Esse cultivar é recomendado para os Estados de SP, MG, PR, SC e RS e possui altura média de $0,81 \mathrm{~m}$ e 0,13 metro de altura média de inserção da primeira vagem (COMIGO, 2005).

Os experimentos foram instalados em um Latossolo Vermelho-Amarelo de textura argilosa, com topografia plana e boa drenagem. A cobertura vegetal foi composta predominantemente pela vegetação nativa de $B$. decumbens em pousio e desenvolvimento vegetativo, com 0,6 a $0,7 \mathrm{~m}$ de estatura. Antes da aplicação dos tratamentos, foram realizadas duas amostragens da cobertura vegetal, aleatoriamente, na área experimental, utilizando-se um quadro vazado de $1,0 \times 1,0 \mathrm{~m}$. O material vegetal foi cortado rente ao solo, acondicionado em sacos de papel e levado para secagem em estufa de circulação forçada de ar, à temperatura de $60^{\circ} \mathrm{C}$ durante 72 horas, para determinação da matéria seca.

Os ensaios foram conduzidos em delineamento inteiramente casualizado, utilizandose três e quatro repetições, respectivamente, nos ensaios com os cultivares BRS 154 e MG/ BR 46-Conquista. Os tratamentos foram constituídos da aplicação de glifosato sobre as plantas de $B$. decumbens aos $28,14,7$ e 0 dias antes e no dia da semeadura da cultura da soja. As parcelas experimentais foram constituídas de uma área de 4,0 x 10,0 m $\left(40 \mathrm{~m}^{2}\right)$, totalizando 12 parcelas para o ensaio com BRS 154 e 16 parcelas para o ensaio com MG/BR 46-Conquista. Utilizou-se $1,30 \mathrm{~kg} \mathrm{ha}^{-1}$ (i.a.) de glifosato, aplicado com pulverizador costal pressurizado por $\mathrm{CO}_{2}$ à pressão constante de $28 \mathrm{lbf} \mathrm{pol}^{-2}$ e munido de uma barra com quatro bicos de jato plano (leque) XR 11002, espaçados de $0,5 \mathrm{~m}$, com consumo de calda equivalente a $170 \mathrm{~L} \mathrm{ha}^{-1}$.

Em ambos os ensaios, as sementes de soja foram submetidas à inoculação com Bradyrhizobium japonicum e tratadas quimicamente com thiram. A semeadura foi realizada mecanicamente, com espaçamento entrelinhas de $0,45 \mathrm{~m}$ e uma população de $330.000 \mathrm{ha}^{-1}$. A adubação de semeadura foi realizada com $5 \mathrm{~kg} \mathrm{ha}^{-1}$ de nitrogênio, $50 \mathrm{~kg} \mathrm{ha}^{-1}$ de $\mathrm{P}_{2} \mathrm{O}_{5}$ e $50 \mathrm{~kg} \mathrm{ha}^{-1}$ de $\mathrm{K}_{2} \mathrm{O}$. Não foi realizado nenhum controle complementar das plantas daninhas após a emergência da cultura, e nenhum outro trato cultural foi realizado entre a semeadura e a colheita.

Foram realizadas avaliações de reinfestação de $B$. decumbens em dois momentos: aos 45 dias após a semeadura (DAS) e no dia da colheita, que aconteceu aos 148 DAS. Para essas avaliações foram atribuídas notas de porcentagem, em que $0 \%$ representava uma parcela totalmente no limpo e $100 \%$, uma parcela totalmente coberta pela espécie infestante. Por ocasião da colheita, foi retirada uma amostra de dez plantas da área útil de cada parcela, para determinação de produtividade, da altura de inserção da primeira vagem e do número de vagens por planta. Para expressão da produtividade e massa de 100 sementes, a massa dos grãos foi corrigida para $13 \%$ de umidade.

Os dados obtidos foram submetidos à análise de variância pelo teste $\mathrm{F}$, e as médias, comparadas pelo teste de Tukey a $5 \%$ de probabilidade.

\section{RESULTADOS E DISCUSSÃO}

O manejo químico de $B$. decumbens formou uma camada de palha de aproximadamente $15 \mathrm{~cm}$ sobre o solo, resultando em $8,6 \mathrm{t} \mathrm{ha}^{-1}$ de matéria seca. Timossi et al. (2006), estudando também a utilização de $B$. decumbens na formação da palhada para o sistema plantio direto, obtiveram $7,4 \mathrm{t} \mathrm{ha}^{-1}$ de matéria seca, enquanto Fagundes et al. (2005) encontraram $4,3 \mathrm{t} \mathrm{ha}^{-1}$ e Nunes et al. (2006) relataram $11 \mathrm{t} \mathrm{ha}^{-1}$ de matéria seca em pastagens naturais da referida forrageira. Entre os fatores responsáveis pelas diferenças de matéria seca obtidas nesses trabalhos, destacam-se as condições edafoclimáticas e os diferentes intervalos de tempo entre a semeadura de $B$. decumbens e o seu manejo químico.

A reinfestação de $B$. decumbens foi maior nas parcelas onde o manejo químico da cobertura foi feito 28 dias antes da semeadura e no manejo químico no mesmo dia da semeadura (Tabela 1). A realização da operação de 
semeadura no mesmo dia do manejo químico ocasiona um dano mecânico nas plantas, pelos discos de corte, de distribuição do fertilizante e de distribuição das sementes, prejudicando a translocação do herbicida na planta; por conseguinte, houve maior rebrote nas parcelas com esse tratamento, contribuindo para sua menor eficácia (Tabela 1). Por isso, esse tratamento apresentou a segunda maior reinfestação na avaliação aos 45 DAS e não diferiu significativamente daquele em que a dessecação foi realizada aos 28 dias antes da semeadura da soja, na avaliação aos 148 DAS. Esses resultados diferem dos encontrados por Oliveira Jr. et al. (2006), que estudaram o manejo químico de Bidens pilosa antes da semeadura da soja e constataram que a principal diferença entre os períodos de manejo químico foi a velocidade de morte das plantas manejadas, que tem implicação direta no grau de cobertura do solo no momento da semeadura.

O período de 28 dias entre o manejo químico de $B$. decumbens e a semeadura da soja permitiu o surgimento de novas plantas de $B$. decumbens, que emergiram praticamente junto com a cultura-fato evidenciado pela reinfestação estatisticamente superior encontrada aos 45 DAS. Em casos como esse, deveria ser realizada uma segunda aplicação do herbicida de manejo químico antes da semeadura, uma aplicação de um herbicida com poder residual em mistura com o glifosato

Tabela 1 - Reinfestação (\%) da área por B. decumbens aos 45 e 148 dias após a semeadura (DAS) nos experimentos com os cultivares BRS 154 e MG/BR 46 - Conquista. Batatais-SP, 2003

\begin{tabular}{|c|c|c|c|c|}
\hline \multirow{2}{*}{ Época } & \multicolumn{2}{|c|}{$\begin{array}{c}\text { Reinfestação aos } \\
\text { 45 DAS (\%) }\end{array}$} & \multicolumn{2}{c|}{$\begin{array}{c}\text { Reinfestação aos } \\
148 \text { DAS }(\%)\end{array}$} \\
\cline { 2 - 5 } & BRS 154 & Conquista & BRS 154 & Conquista \\
\hline 28 & $87,50 \mathrm{a}$ & $88,33 \mathrm{a}$ & $73,75 \mathrm{a}$ & $93,33 \mathrm{a}$ \\
\hline 14 & $6,25 \mathrm{c}$ & $18,33 \mathrm{c}$ & $37,50 \mathrm{~b}$ & $11,67 \mathrm{~b}$ \\
\hline 7 & $10,00 \mathrm{c}$ & $11,67 \mathrm{c}$ & $43,75 \mathrm{~b}$ & $18,33 \mathrm{~b}$ \\
\hline 0 & $22,50 \mathrm{~b}$ & $46,67 \mathrm{~b}$ & $81,25 \mathrm{a}$ & $90,00 \mathrm{a}$ \\
\hline Teste F & $133,14^{* *}$ & $51,48^{* *}$ & $18,23 * *$ & $78,74^{* *}$ \\
\hline DMS & 14,53 & 22,01 & 22,42 & 22,65 \\
\hline CV\% & 14,6 & 20,4 & 17,2 & 16,2 \\
\hline
\end{tabular}

** Significativo a $1 \%$ de probabilidade.

Médias seguidas por letras iguais, na mesma coluna, não diferem entre si pelo teste de Tukey a $5 \%$ de probabilidade na operação de manejo químico ou um controle complementar após a emergência da cultura. Timossi et al. (2006) afirmam que o controle de $B$. decumbens e $B$. brizantha pela aplicação de glifosato foi muito bom a partir da dosagem de $2,16 \mathrm{~kg} \mathrm{ha}^{-1}$ (i.a.), embora também não tenha sido capaz de evitar totalmente os rebrotes. Os intervalos de 7 e 14 dias mantiveram a cultura praticamente no limpo até a colheita, pois, além da maior eficácia no controle da cobertura vegetal, o surgimento de um novo fluxo de $B$. decumbens foi suprimido pelo fechamento do espaço entre os dosséis.

Para a soja MG/BR46-Conquista não foi encontrada diferença estatística entre os tratamentos na avaliação de altura de inserção da primeira vagem (Tabela 2), enquanto para o cultivar BRS 154 o manejo químico de $B$. decumbens 28 dias antes da semeadura aumentou a altura de inserção da primeira vagem das plantas de soja, provavelmente devido a uma resposta à maior e mais precoce matocompetição. O número de vagens por planta não foi afetado significativamente por nenhum dos tratamentos testados.

A reinfestação ocorrida nas parcelas manejadas no dia da semeadura e aos 28 dias antes da semeadura, associada à matocompetição e a possíveis efeitos alelopáticos, ocasionou atraso no desenvolvimento das plantas de soja do cultivar BRS 154, fato esse

Tabela 2 - Altura de inserção da primeira vagem (cm) e número de vagens por planta nos experimentos com os cultivares BRS 154 e MG/BR 46 - Conquista. Batatais-SP, 2003

\begin{tabular}{|c|c|c|c|c|}
\hline \multirow{2}{*}{ Época } & \multicolumn{2}{|c|}{$\begin{array}{c}\text { Altura de inserção 1 } \\
\text { vagem }(\mathrm{cm})\end{array}$} & \multicolumn{2}{c|}{$\begin{array}{c}\text { Número de } \\
\text { vagens/planta }\end{array}$} \\
\cline { 2 - 5 } & BRS 154 & Conquista & BRS 154 & Conquista \\
\hline 28 & $21,48 \mathrm{a}$ & 28,07 & 49,85 & 33,90 \\
\hline 14 & $17,85 \mathrm{~b}$ & 29,40 & 65,80 & 61,30 \\
\hline 7 & $17,48 \mathrm{~b}$ & 26,11 & 56,70 & 56,87 \\
\hline 0 & $16,65 \mathrm{~b}$ & 25,00 & 58,60 & 59,23 \\
\hline Teste F & $11,65^{* *}$ & $2,13^{\text {ns }}$ & $2,28^{\text {ns }}$ & $2,72^{\text {ns }}$ \\
\hline DMS & 2,76 & 6,11 & 19,20 & 34,83 \\
\hline CV\% & 6,8 & 8,6 & 15,1 & 25,2 \\
\hline
\end{tabular}

${ }^{\text {ns }}$ Não significativo; $e^{* *}$ significativo a $1 \%$ de probabilidade. Médias seguidas por letras iguais, na mesma coluna, não diferem entre si pelo teste de Tukey a $5 \%$ de probabilidade. 
que pode ser mensurado por meio da umidade dos grãos na época da colheita (Tabela 3). Esse atraso na maturidade dos grãos retarda a colheita, deixando a cultura suscetivel por um maior período a pragas e doenças de final de ciclo, além da possibilidade de inviabilizar o cultivo da segunda safra (safrinha), devido à perda da época ideal de semeadura. A massa média de 100 sementes foi estatisticamente superior quando o manejo químico foi realizado aos 14 e 7 dias antes da semeadura, como pode ser observado na Tabela 3.

As maiores produtividades foram encontradas nas parcelas manejadas nos periodos de 7 e 14 dias antes da semeadura, e os dois cultivares apresentaram comportamentos semelhantes (Figura 1). O manejo químico da cobertura vegetal nesse intervalo de tempo proporcionou, em média, incremento de $46 \%$ no rendimento de grãos de soja, se comparado ao de outros períodos testados. A produtividade média nessas parcelas foi superior à média brasileira $\left(2.600 \mathrm{~kg} \mathrm{ha}^{-1}\right)$ dos últimos quatro anos (FNP, 2005). Em trabalho realizado por Oliveira Jr et al. (2006), o controle de B. pilosa realizado na data da semeadura ou dez dias antes prejudicou o desenvolvimento da soja, resultando em queda na produtividade entre 10 e $20 \%$, se comparado ao manejo químico realizado apenas aos 20 dias antes da semeadura. Ainda segundo esses autores, os métodos de controle complementar (manual, aplicação sequencial ou em dose única de herbicidas após a emergência da cultura) proporcionaram incremento de produtividade em relação à não realização do controle, o que reflete a interferência imposta pelas plantas daninhas na soja.

Nepomuceno et al. (2007) relataram que a interferência das plantas daninhas Alternanthera tenella, Cenchrus echinatus e $B$. pilosa durante todo o ciclo da cultura reduziu, em média, $46 \%$ a produtividade de grãos da soja, sem afetar significativamente a estatura das plantas, a altura de inserção da primeira vagem e o número de vagens por planta. Procópio et al. (2006) compararam o efeito de diferentes sistemas de manejo químico no controle de Digitaria insularis, Synedrellopsis grisebachii e Leptochloa filiformis e verificaram que os melhores resultados de controle foram obtidos com aplicações de glifosato cinco dias antes da semeadura da soja ou com a aplicação antecipada (10 a 20 dias antes da semeadura), com posterior aplicação da mistura paraquat+diuron na data da semeadura.

Com base nos resultados encontrados, pode-se concluir que: $B$. decumbens produz quantidade de palha suficiente para sua indicação como opção para incorporar e manter biomassa ao longo do tempo em áreas de sistema plantio direto em regiões de clima tropical; a época mais adequada para o manejo químico dessa espécie situa-se entre 7 e 14 dias antes da semeadura da soja; e a

Tabela 3 - Umidade dos grãos (\%) e de massa de 100 sementes (g) nos experimentos com os cultivares BRS 154 e MG/BR 46 - Conquista. Batatais-SP, 2003

\begin{tabular}{|c|c|c|c|c|}
\hline \multirow{2}{*}{ Época } & \multicolumn{2}{|c|}{$\begin{array}{c}\text { Umidade dos grãos } \\
(\%)\end{array}$} & \multicolumn{2}{c|}{$\begin{array}{c}\text { Massa de } 100 \text { sementes } \\
\text { (g) }\end{array}$} \\
\cline { 2 - 5 } & BRS 154 & Conquista & BRS 154 & Conquista \\
\hline 28 & $15,36 \mathrm{a}$ & 14,09 & $11,59 \mathrm{~b}$ & $11,56 \mathrm{~b}$ \\
\hline 14 & $13,85 \mathrm{~b}$ & 11,25 & $13,00 \mathrm{a}$ & $12,96 \mathrm{a}$ \\
\hline 7 & $13,33 \mathrm{~b}$ & 11,70 & $12,97 \mathrm{a}$ & $12,69 \mathrm{a}$ \\
\hline 0 & $16,25 \mathrm{a}$ & 15,36 & $10,92 \mathrm{~b}$ & $10,35 \mathrm{~b}$ \\
\hline Teste F & $6,25^{*}$ & $1,17^{\text {ns }}$ & $7,31^{* *}$ & $9,73^{* *}$ \\
\hline $\mathrm{DMS}$ & $1,-\mathrm{H}$ & 8,18 & 1,25 & 1,35 \\
\hline $\mathrm{CV} \%$ & 13,1 & 23,9 & 6,3 & 7,5 \\
\hline
\end{tabular}

${ }^{\text {ns }}$ Não significativo; $*$ significativo a $5 \%$ de probabilidade; e $* *$ ignificativo a $1 \%$ de probabilidade

Médias seguidas por letras iguais, na mesma coluna, não diferem entre si pelo teste de Tukey a $5 \%$ de probabilidade.

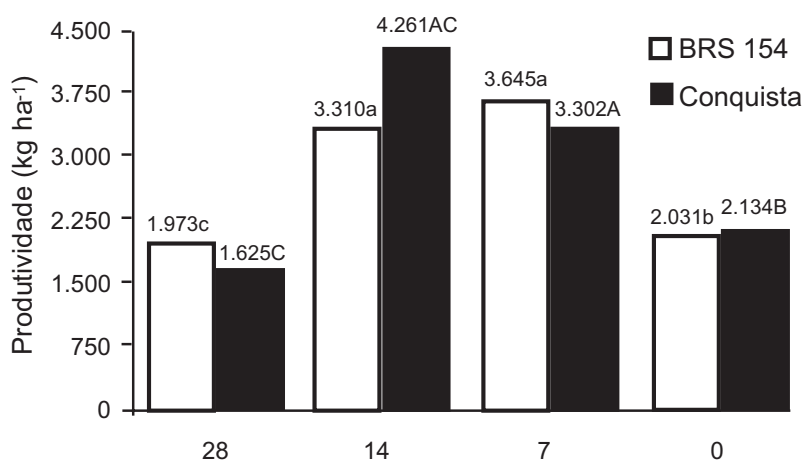

Médias com a mesma letra, no mesmo cultivar, não diferem significativamente pelo teste de Tukey a $5 \%$ de probabilidade.

Figura 1 - Produtividade média $\left(\mathrm{kg} \mathrm{ha}^{-1}\right)$ nos experimentos com os cultivares BRS 154 e MG/BR 46 - Conquista, semeados 28, 14, 7 dias após e no dia do manejo químico com glifosato. Batatais-SP, 2003 
escolha da época de manejo químico dessa cobertura vegetal afeta de forma decisiva o desenvolvimento da cultura e a dinâmica populacional das plantas daninhas.

\section{LITERATURA CITADA}

COOPERATIVA MISTA DOS PRODUTORES RURAIS DO SUDOESTE GOIANO - COMIGO. Variedades de soja. Disponível em: <www.comigo.com.br/arquivos/ variedades2005.doc>. Acesso em: 5 nov. 2007.

CONSTANTIN, J.; MACIEL, C. D. G.; OLIVEIRA JR., R. $\mathrm{S}$. Sistemas de manejo em plantio direto e sua influência sobre herbicidas aplicados em pós-emergência na cultura da soja.

R. Bras. Herbic., v. 1, n. 3, p. 233-242, 2000.

FAGUNDES, J. L. et al. Acúmulo de forragem em pastos de Brachiaria decumbens adubados com nitrogênio. Pesq.

Agropec. Bras., v. 40, n. 4, p. 397-403, 2005.

FNP Consultorias \& Comércio. Agrianual 2005: Anuário da agricultura brasileira. São Paulo: 2005. p. 484.

MACIEL, C. D. G. et al. Influência do manejo da palhada de capim-braquiária (Brachiaria decumbens) sobre o desenvolvimento inicial de soja (Glycine max) e amendoimbravo (Euphorbia heterophylla). Planta Daninha, v. 21, n. 3 , p. 365-373, 2003.

MELHORANÇA, A. L.; VIEIRA, C. P. Efeito da época de dessecação sobre o desenvolvimento e produção da soja. In: REUNIÃO DE PESQUISA DE SOJA DA REGIÃO CENTRAL DO BRASIL, 21., 1999, Dourados. Resumos... Dourados: Embrapa Agropecuária Oeste, 1999. p. $224-225$
NEPOMUCENO, M. et al. Períodos de interferência das plantas daninhas na cultura da soja nos sistemas de semeadura direta e convencional. Planta Daninha, v. 25, n. 1, p. 43-50, 2007.

NUNES, U. R. et al. Produção de palhada de plantas de cobertura e rendimento do feijão em plantio direto. Pesq. Agropec. Bras., v. 41, n. 6, p. 943-948, 2006.

OLIVEIRA Jr., R. S. et al. Interação entre sistemas de manejo e de controle de plantas daninhas em pós-emergência afetando o desenvolvimento e a produtividade da soja. Planta

Daninha, v. 24, n. 4, p. 721-732, 2006

PEIXOTO, M. F.; SOUZA, I. F. Efeitos de doses de imazamox e densidades de sorgo (Sorghum bicolor (L.) Moench) em soja (Glycine max (L.) Merr.) sob plantio direto. Ci. Agrotec., v. 26, n. 2, p. 252-258, 2002.

PROCÓPIO, S. O. et al. Efeitos de dessecantes no controle de plantas daninhas na cultura da soja. Planta Daninha, v. 24, n. 1, p. 193-197, 2006.

SANTOS, J. B. I. et al. Época de dessecação anterior à semeadura sobre o desenvolvimento da soja resistente ao glyphosate. Planta Daninha, v. 25, n. 4, p. 869-875, 2007.

SILVA, A. C. et al. Micorrização e épocas de dessecação de Brachiaria brizantha no desenvolvimento da soja. Planta Daninha, v. 24, n. 2, p. 271-277, 2006

SOUZA, L. S. et al. Efeito alelopático de capim-braquiária (Brachiaria decumbens) sobre o crescimento inicial de sete espécies de plantas cultivadas. Planta Daninha, v. 24, n. 4, p. $657-668,2006$.

TIMOSSI, P. C.; DURIGAN, J. C.; LEITE, G. J. Eficácia de glyphosate em plantas de cobertura. Planta Daninha, v. 24, n. 3, p. 475-480, 2006. 